\section{INCENTIVES AND SIZE OF INDUSTRIAL PLANT IN GREAT BRITAIN}

$\mathrm{T}$ HE information about the "Proportion of Timeworkers and Pieceworkers" which is published by the Ministry of Labour ${ }^{1}$ may be expected to direct inquiries on industrial structure into new channels. A remarkable connexion between the distribution of pieceworkers and the variation of the size of plants emerges from this information, a connexion which in the past seems to have been overlooked by both theoretical and empirical studies in this field.

The first detailed survey of methods of wage payments in separate industries appeared in 1947; it was followed by two similar but more elaborate surveys, for October 1949 and October 1951. A new feature of these two is the classification of the data according to the size of industrial plants. Four sizeclasses are distinguished: establishments with less than $25,25-99,100-499$, and with 500 or more wage-earners. Pieceworkers are defined as workers paid under any system of "payment by results", and data are supplied for 131 separate (mostly manufacturing) industries. The 1951 survey covers some $6 \frac{1}{2}$ million workers, which amounts to more than two-thirds of the total number employed in the 131 industries.

To appreciate this material it should be recalled that the Census of Production gives data on size of plants and wages but not on wage methods. Although it might seem plausible that incentive schemes are more suitable for larger than for smaller plants, there has been no evidence of this. Indeed, it is known that they are widely used in such industries as cotton, potteries, dressmaking, etc., where relatively small and medium, rather than large, plants prevail. Thus, a close relationship between an industry's sizestructure and particular payment methods could scarcely be expected. That it does exist, nevertheless, can now be seen from the Ministry of Labour surveys. We must exclude, of course, those industries where the proportion of pieceworkers as a whole is too small (say, less than 10 per cent) to be significant for the present purpose or where the information for separate size-classes is incomplete. There remain seventy-five industries, and forty-seven of these show a consistent relation between size-structure and incentives: the proportion of pieceworkers increases step by step with increasing size of plant. In iron and steel melting and rolling, for example, the percentage of pieceworkers rises from class I (less than 25 workers) to class IV (500 and more), in 1949, as follows : 25,37 , 51 and 65 per cent; and similarly in 1951: 24, 41, 54 and 66 per cent. Other important industries with the same pattern are motor-vehicles, rayon and nylon weaving, building, boots and shoes, rubber, furniture and iron foundries. The industries which do not show a connexion between size of plant and methods of payment include woollen and worsted, cotton weaving, tailoring and agricultural machinery.

While a full explanation must wait for further data, two conclusions may already be suggested. The specific advantages of larger organizations are not only a matter of technical conditions, but involve also the opportunity of controlling a relatively larger number of workers through wage incentives; and the possibility of increasing the use of incentives, on the other hand, depends at least partly on the scope for expansion. There can be no doubt that the
Ministry of Labour surveys are extremely useful for the advancement of research into these problems. It would be desirable, however, if in future actual figures of wage-earners, not merely percentages, could be supplied, and if the largest size-class could be split up into 500-999 and 1,000 and more workers. It would then be possible to link up the information with the Census of Production. W. BaLdamus

Min. Lab. Gazette, October 1947, October 1950 and April 1952.

\section{EAST AFRICAN INDUSTRIAL RESEARCH BOARD}

\section{REPORT FOR 1951}

$T$ HE ninth annual report of the East African Industrial Research Board* covers activities for the year ending December 31, 1951. Laboratory trials described in the last annual report have been followed by an experimental run at a factory producing sodium phosphate commercially, which has demonstrated that a satisfactory product can be obtained in a continuous chamber kiln fired by wood producergas, with proper control of firing. Storage trials over a period of three months have demonstrated that there is no deterioration of this type of product, provided there is no marked leaching.

The characteristics of cement clinker obtained by burning varying proportions of a product containing less than $0 \cdot 5$ per cent of phosphorus pentoxide, from limestone containing 2 per cent of phosphorus pentoxide, with raw limestone and clay are being investigated, and also the effect on refractory quality of bonding different grain-sizes of kyanite with various materials. Two new clay deposits have been found which proved satisfactory bond clays for refractories, and certain lavas have been found which can form the basis of a glaze for drain-pipes and which can be fired at a lower temperature than that required for salt glazing. The distillation of surplus wood from the wattle industry to give charcoal and wood tar is being investigated, and metallurgical charcoal obtained from wattle may be of use for smelting and other purposes in the Tororo area. Simple pulverization reduced the bulk density of the husk from diried coffee cherry sufficiently to permit its transportation for use as a substitute for bran in stock feeds. Mixed fatty acids obtained from the seeds of Moringa oleifera are highly suitable for froth flotation in the production of kyanite, and a drying oil which is satisfactory for paint manufacture has been obtained in 17 per cent yield from the whole nuts of Aleurites triloba, grown in Uganda, and in 55 per cent yield from the kernels.

Hecogenin, a steroid, which can be used as a raw material for the synthesis of cortisone, can be conveniently obtained from the juice of the sisal leaf, and a pilot plant has been built at the laboratory to provide the Medical Research Council with a supply of hecogenin for the synthesis of cortisone. A note appended to the report outlines the process and indicates the work which an officer of the National Institute for Medical Research is carrying out on the occurrence of hecogenin in sisal leaves. A note on the drying of sisal fibre and a list of publications on industrial research are also appended.

* East African Industrial Research Board. Ninth Annual Report 1951. Fp. 10. (Nairobi : Government Printer, 1952.) 